\title{
Sensory evaluation of edoxaban orally disintegrating tablets: an open-label interventional study (secondary publication)
}

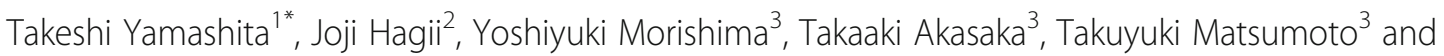
Tetsuya Kimura ${ }^{3}$

\begin{abstract}
Background: This study involved a sensory evaluation of edoxaban orally disintegrating (OD) tablets in patients with nonvalvular atrial fibrillation who had been receiving the existing edoxaban film-coated tablets before the study.

Methods: Edoxaban OD tablets 30 or $60 \mathrm{mg}$ were prescribed for patients who had been receiving the existing 30- or 60-mg edoxaban film-coated tablets before the study. Each dose group was randomized into groups taking the tablets with or without water. After ingestion of the edoxaban OD tablet, each patient was asked to complete a sensory evaluation questionnaire (12 items).

Results: In the evaluation of satisfaction with edoxaban OD tablets, 52.8\% of the patients perceived "no difference" from the existing edoxaban film-coated tablets and $34.9 \%$ indicated that they were more satisfied with the OD tablets, thus demonstrating a relatively high degree of satisfaction. When asked about convenience and reliability in using edoxaban OD tablets, about half of the patients perceived "no difference" from the existing edoxaban film-coated tablets and the remaining half indicated preference for the OD tablets. Responses about taste, flavor, ease of ingestion, and motivation to continue taking edoxaban indicated the overall acceptance of the OD tablets. Recognition of edoxaban OD tablets was rated as "easy" by about half of the patients and "difficult" by the remaining half. Among all patients, 49.5\% preferred a change to edoxaban OD tablets. The degree of satisfaction with taste, flavor, and ease of ingestion, as well as overall satisfaction, tended to be greater when the OD tablets were taken with rather than without water, and the percentage of patients who preferred a change was higher in the group taking the OD tablets with water.

Conclusions: This study indicated that the degree of satisfaction with taste, flavor, ease of ingestion, and convenience, as well as overall satisfaction, in addition to motivation to continue drug intake and sense of confidence were greater for OD tablets than for the existing edoxaban film-coated tablets. Edoxaban OD tablet is a promising formulation for inducing greater patient adherence to medication and therefore ensures better treatment response.
\end{abstract}

Trial registration: UMIN-CTR UMIN000028788, registered 23-Aug-2017.

Keywords: Edoxaban, Nonvalvular atrial fibrillation, Orally disintegrating (OD) tablet, Sensory evaluation

\footnotetext{
* Correspondence: yamt-tky@umin.ac.jp

${ }^{1}$ The Cardiovascular Institute, 3-2-19, Nishiazabu, Minato-ku, Tokyo 106-0031,

Japan

Full list of author information is available at the end of the article
}

(C) The Author(s). 2019 Open Access This article is distributed under the terms of the Creative Commons Attribution 4.0 International License (http://creativecommons.org/licenses/by/4.0/), which permits unrestricted use, distribution, and reproduction in any medium, provided you give appropriate credit to the original author(s) and the source, provide a link to the Creative Commons license, and indicate if changes were made. The Creative Commons Public Domain Dedication waiver (http://creativecommons.org/publicdomain/zero/1.0/) applies to the data made available in this article, unless otherwise stated. 


\section{Background}

Some patients with diseases requiring anticoagulant therapy such as atrial fibrillation have impaired swallowing function due to reasons including advanced age and history of stroke [1]. Decreased medication adherence in these patients could be attributable to difficulty of taking standard tablets. Improvement of medication adherence is essential for a safe and effective anticoagulant therapy, as anticoagulants require long-term use. Use of orally disintegrating (OD) tablets is one way of improving medication adherence. OD tablets are easy to be taken by patients with restricted water ingestion, the elderly, and those with difficulty swallowing because they readily disintegrate in the oral cavity and can be taken anywhere without water. Thus, the use of OD tablets is expected to improve medication adherence, which results in improved therapeutic performance. Patients who changed from standard tablets to OD tablets have been reported to show improvement of medication adherence and therapeutic efficacy $[2,3]$.

Edoxaban (product name in Japan: Lixiana ${ }^{\circ}$ ) is a direct oral anticoagulant (DOAC) with indications for prevention of stroke and systemic embolism in patients with nonvalvular atrial fibrillation and treatment and prevention of recurrent venous thromboembolism, among others. Since 2017, edoxaban OD tablet, which is the first OD tablet formulation of DOACs, has been marketed in Japan.

This questionnaire survey was conducted for sensory evaluation of edoxaban OD tablets (a single dose of 30 or $60 \mathrm{mg}$ ) to assess the impression upon ingestion, sense of convenience, ease of recognition as edoxaban OD tablets, and desire to switch to edoxaban OD tablets in patients with nonvalvular atrial fibrillation who had been receiving existing edoxaban film-coated tablets (30 or $60 \mathrm{mg}$ ) before the study.

\section{Methods \\ Patients}

This study included 108 patients aged $\geq 20$ years who had nonvalvular atrial fibrillation and visited the Cardiovascular Institute Hospital or Hirosaki Stroke and Rehabilitation Center between August 2017 and January 2018. All patients had been receiving 30- or 60-mg edoxaban filmcoated tablets for $\geq 2$ weeks, and provided written consent to participate in this study.

The following patients were excluded: those receiving dual antiplatelet therapy; those with a cardiovascular event (stroke, myocardial infarction, cardiac intervention other than myocardial infarction, or heart failure requiring hospitalization) or those hospitalized for bleeding within 2 weeks before enrollment; or those who were pregnant, lactating, or possibly pregnant.

\section{Study design}

This was an open-label interventional study, with patients given a single dose of one edoxaban OD tablet (30 or $60 \mathrm{mg})$.

On the day of the visit, each patient underwent blood sampling for measuring prothrombin time to confirm that no edoxaban tablet had been taken that day. A corresponding 30 - or $60-\mathrm{mg}$ edoxaban OD tablet was prescribed for each patient who had been receiving 30- or 60-mg edoxaban film-coated tablets before the start of the study. Each of these 2 groups was subdivided randomly into 2 groups (taking an OD tablet with or without water) in an allocation ratio of 1:1 (4 groups in total). A dynamic allocation was performed using study site, age at enrollment ( $\geq 75$ or $<75$ years), and sex as adjustment factors to avoid their influence on outcome. Simultaneous ingestion of edoxaban OD tablet with any other drugs was prohibited. The target total number of participants was 100 patients in 4 groups (set at 20 or 30 patients/group), in accordance with previous clinical studies on sensory evaluation of OD tablets [4-6].

After ingestion of the 30- or 60-mg edoxaban OD tablet, each patient was asked to answer all 12 questions in the sensory evaluation questionnaire (Table 1), and the answers to each question were analyzed. An open-ended answer was permitted for the "Reason for the selected answer."

Safety was assessed by recording any adverse events (AEs) from immediately after ingestion of edoxaban OD tablets to the following day.

The protocol was registered with the open database UMIN Clinical Trials Registry (Trial ID: UMIN0000 28788) prior to the start of the study, and the summarized results were also registered after completion of the study.

\section{Statistical analyses}

For patient background characteristics and answers to the sensory evaluation questionnaire (12 items), summary statistics for continuous data and numbers and percentages for categorical data were calculated. For safety evaluation, the number of patients with AEs or adverse drug reactions (ADRs) was counted.

These analyses were conducted for the subgroups (age $<75$ or $\geq 75$ years; presence or absence of difficulty taking the current medication). These statistical analyses were performed using SAS Ver. 9.4.

\section{Results}

In total, 108 patients were enrolled and allocated for this study. The 66 patients who were receiving 30-mg edoxaban film-coated tablets before the start of the study were allocated to group 1 (30-mg edoxaban OD tablet without water; $n=33$ ) and group $3(30$-mg edoxaban OD tablet with water; $n=33$ ). The 42 patients 
Table 1 Sensory evaluation questionnaire

$$
\text { Question }
$$

Please answer the questions about the drugs you are routinely taking.

Question 1 Have you ever found difficulty taking any of the tablets you are routinely taking?

1. Yes 2. No

Question 2 Have you ever been unable to identify the drug taken out of the sheet, causing you to stop taking the drug or any other difficulty? 1. Yes 2. No

Question 3 How many types of drugs are you routinely taking every morning, including the edoxaban film-coated tablet? [types]

Next, please answer the questions about the edoxaban orally disintegrating (OD) tablet you have just taken.

Question 4 What is the extent of your satisfaction with the edoxaban OD tablet you have just taken, if your satisfaction with the current medication (edoxaban film-coated tablet) rates 5 ?

Quite unsatisfactory

No difference

Quite satisfactory

$\begin{array}{lllllllllll}0 & 1 & 2 & 3 & 4 & 5 & 6 & 7 & 8 & 9 & 10\end{array}$

Question 5 The product name and dose level are printed on this tablet. Was it easy for you to identify that the drug was edoxaban OD tablet $30 \mathrm{mg}$ or $60 \mathrm{mg}$ ?

1. Quite easy to identify

2. Easier to identify than the current edoxaban film-coated tablet

3. More difficult to identify than the current edoxaban film-coated tablet

4. Quite difficult to identify

Question 6 What was your impression about the size of this tablet when you placed it in your mouth?

1. Very large

2. Slightly large

3. Slightly small

4. Very small

Question 7 What was your impression of the taste and flavor of this drug when it disintegrated in your mouth?

1. Very good

2. Relatively good

3. Relatively bad (i: Tolerable, ii: Not tolerable)

4. Very bad (i: Tolerable, ii: Not tolerable)

$\rightarrow$ Please give the reason for selecting 1 through 4 , if possible:

[Reason:]

Question 8 Have you found this drug easier to take than the current medication (edoxaban film-coated tablet)?

1. Quite easy to take

2. Slightly easier to take

3. No difference

4. Slightly more difficult to take

5. Quite difficult to take

$\rightarrow$ Please give the reason for selecting 1 through 5 , if possible:

[Reason:]

This drug can be taken both with or without water, and simultaneously with other drugs. The product name and dose level are printed on this tablet.

Question 9 Do you think that this drug is more convenient to take than the current medication (edoxaban film-coated tablet)?

1. Much more convenient

2. Slightly more convenient

3. No difference

4. Slightly less convenient

5. Much less convenient 
Table 1 Sensory evaluation questionnaire (Continued)

\begin{tabular}{|c|c|}
\hline & Question \\
\hline & $\begin{array}{l}\rightarrow \text { Please give the reason for selecting } 1 \text { through } 5 \text {, if possible: } \\
\text { [Reason:] }\end{array}$ \\
\hline \multirow[t]{7}{*}{ Question 10} & Do you think this drug is easier to continue than the current medication (edoxaban film-coated tablet)? \\
\hline & 1. Much easier to continue \\
\hline & 2. Slightly easier to continue \\
\hline & 3. No difference \\
\hline & 4. Slightly less easy to continue \\
\hline & 5. Much less easy to continue \\
\hline & $\begin{array}{l}\rightarrow \text { Please give the reason for selecting } 1 \text { through } 5 \text {, if possible: } \\
\text { [Reason:] }\end{array}$ \\
\hline \multirow[t]{6}{*}{ Question 11} & $\begin{array}{l}\text { Do you think that the printed product name and dose level on the tablet make this drug more reliable than the current medication } \\
\text { (edoxaban film-coated tablet)? }\end{array}$ \\
\hline & 1. Much more reliable \\
\hline & 2. Slightly more reliable \\
\hline & 3. No difference \\
\hline & 4. Slightly less reliable \\
\hline & 5. Much less reliable \\
\hline \multirow[t]{4}{*}{ Question 12} & $\begin{array}{l}\text { This drug will be sold at the same price as the current medication (edoxaban film-coated tablet). Will you want to change to this } \\
\text { drug after marketed? }\end{array}$ \\
\hline & 1. Desire to change \\
\hline & 2. No desire to change \\
\hline & $\begin{array}{l}\rightarrow \text { Please give the reason for selecting } 1 \text { or } 2 \text {, if possible: } \\
\text { [Reason:] }\end{array}$ \\
\hline
\end{tabular}

who had been receiving 60-mg edoxaban film-coated tablets before the start of the study were allocated to group 2 (60-mg edoxaban OD tablet without water; $n=21$ ) and group 4 (60-mg edoxaban OD tablet with water; $n=21)$.

Nine patients (group 1, $n=4$; group 3, $n=3$; and group $4, n=2$ ) discontinued the study because of violation of the inclusion/exclusion criteria $(n=8)$ and cancellation of the study drug administration at the discretion of the physician $(n=1)$. The efficacy analysis set included 106 of 108 patients, excluding 1 patient with a serious violation of the study protocol and 1 patient in whom the administration was cancelled at the discretion of the physician. The safety analysis set included 107 patients, excluding 1 patient in whom the administration was cancelled at the discretion of the physician.

\section{Background characteristics}

Table 2 shows the background characteristics of the efficacy analysis set $(n=106)$. The patients' mean $( \pm$ standard deviation) age was $73.0 \pm 8.6$ years. Of the patients, $49.1 \%$ $(52 / 106)$ were aged $\geq 75$ years and $60.4 \%(64 / 106)$ were men. For the 79 patients who had data on height, the mean height was $161.6 \pm 10.0 \mathrm{~cm}$. The mean body weight was $61.1 \pm 13.5 \mathrm{~kg}$.

\section{Sensory evaluation questionnaire}

For the efficacy analysis set $(n=106)$, the responses to the sensory evaluation questionnaire for the total and subgroups are shown in Fig. 1 and Table 3, respectively. Questions 1-3 pertain to the current medication, and questions 4-12 pertain to edoxaban OD tablets.

\section{Current medication}

For question 1 (Have you ever found difficulty taking any of the tablets you are routinely taking?), 13.2\% (14/106) of the respondents answered "Yes."

For question 2 (Have you ever been unable to identify the drug taken out of the sheet, causing you to stop taking the drug or any other difficulty?), 6.6\% (7/106) selected "Yes."

For question 3 (How many types of drugs are you routinely taking every morning, including the edoxaban film-coated tablet?), "three types or more" was selected most frequently $(78.3 \%, 83 / 106)$, followed by "2 types" $(12.3 \%, 13 / 106)$ and " 1 type (edoxaban film-coated tablet alone)" (9.4\%, 10/106).

\section{Edoxaban $O D$ tablets}

For question 4. (What is the extent of your satisfaction with the edoxaban OD tablet you have just taken, if your 
Table 2 Background characteristics (efficacy analysis set)

\begin{tabular}{|c|c|c|c|}
\hline & & $\mathrm{n}$ & Mean \pm SD or $\%$ \\
\hline \multirow[t]{5}{*}{ Age, $y$, mean $\pm S D$} & Total & 106 & $73.0 \pm 8.6$ \\
\hline & 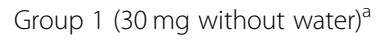 & 32 & $77.0 \pm 6.2$ \\
\hline & Group 3 (30 mg with water) & 32 & $76.7 \pm 6.3$ \\
\hline & Group 2 (60 mg without water) ${ }^{c}$ & 21 & $67.7 \pm 8.9$ \\
\hline & Group 4 (60 mg with water) ${ }^{d}$ & 21 & $66.9 \pm 8.3$ \\
\hline \multirow[t]{5}{*}{ Age ( $\geq 75$ years old), \% } & Total & 52 & 49.1 \\
\hline & Group 1 (30 mg without water) ${ }^{a}$ & 21 & 65.6 \\
\hline & Group 3 (30 mg with water) ${ }^{b}$ & 20 & 62.5 \\
\hline & Group $2(60 \mathrm{mg} \text { without water })^{c}$ & 6 & 28.6 \\
\hline & Group 4 (60 mg with water) ${ }^{d}$ & 5 & 23.8 \\
\hline \multirow[t]{5}{*}{ Male, \% } & Total & 64 & 60.4 \\
\hline & Group 1 (30 mg without water) $^{\mathrm{a}}$ & 11 & 34.4 \\
\hline & Group 3 (30 mg with water) ${ }^{b}$ & 12 & 37.5 \\
\hline & Group 2 (60 mg without water) ${ }^{c}$ & 21 & 100.0 \\
\hline & Group 4 (60 mg with water) ${ }^{d}$ & 20 & 95.2 \\
\hline \multirow[t]{5}{*}{ Height, $\mathrm{cm}$, mean \pm SD } & Total & 79 & $161.64 \pm 9.97$ \\
\hline & Group 1 (30 mg without water) ${ }^{a}$ & 24 & $156.79 \pm 8.43$ \\
\hline & Group 3 (30 mg with water) ${ }^{b}$ & 24 & $156.25 \pm 7.19$ \\
\hline & Group 2 (60 mg without water) ${ }^{c}$ & 17 & $170.69 \pm 7.93$ \\
\hline & Group 4 (60 mg with water) ${ }^{d}$ & 14 & $168.19 \pm 7.22$ \\
\hline \multirow[t]{5}{*}{ Body weight, $\mathrm{kg}$, mean $\pm \mathrm{SD}$} & Total & 106 & $61.12 \pm 13.49$ \\
\hline & Group 1 (30 mg without water) ${ }^{a}$ & 32 & $52.69 \pm 7.38$ \\
\hline & Group 3 (30 mg with water) ${ }^{b}$ & 32 & $52.80 \pm 6.71$ \\
\hline & Group 2 (60 mg without water) ${ }^{c}$ & 21 & $71.85 \pm 11.13$ \\
\hline & Group 4 (60 mg with water) ${ }^{d}$ & 21 & $75.91 \pm 10.09$ \\
\hline \multirow[t]{5}{*}{ Prior cerebral infarction/transient ischemic attack, \% } & Total & 46 & 43.4 \\
\hline & Group 1 (30 mg without water) $^{\mathrm{a}}$ & 17 & 53.1 \\
\hline & Group 3 (30 mg with water) $)^{b}$ & 14 & 43.8 \\
\hline & Group 2 (60 mg without water) ${ }^{c}$ & 8 & 38.1 \\
\hline & Group 4 (60 mg with water) ${ }^{d}$ & 7 & 33.3 \\
\hline
\end{tabular}

${ }^{a}$ Edoxaban OD tablet $30 \mathrm{mg}$ without water

bedoxaban OD tablet $30 \mathrm{mg}$ with water

'edoxaban OD tablet $60 \mathrm{mg}$ without water

dedoxaban OD tablet $60 \mathrm{mg}$ with water

$O D$ orally disintegrating, $S D$ standard deviation

satisfaction with the current medication [edoxaban film-coated tablet] rates 5 ?), the answers on the 11-grade scale are shown in Fig. 2. "No difference (rating: 5)" was selected most frequently $(52.8 \%, 56 / 106)$, followed by "satisfactory (rating: 6-10)" (34.9\%, 37/106) and "unsatisfactory (rating: 0-4)" (12.3\%, 13/106) (Fig. 1).

For question 5 (The product name and dose level are printed on this tablet. Was it easy for you to identify that the drug was edoxaban OD tablet $30 \mathrm{mg}$ or $60 \mathrm{mg}$ ?), "quite difficult to identify" was selected most frequently $(30.5 \%, 32 / 105)$, followed by "easier to identify than the current edoxaban film-coated tablet" $(27.6 \%, 29 / 105)$, "quite easy to identify" (26.7\%, 28/105), and "more difficult to identify than the current edoxaban film-coated tablet" $(15.2 \%, 16 / 105)$.

For question 6 (What was your impression about the size of this tablet when you placed it in your mouth?), "slightly large" was selected most frequently $(59.2 \%, 58 / 98)$, followed by "slightly small" $(37.8 \%, 37 / 98)$, "very large" $(2.0 \%, 2 / 98)$, and "very small" $(1.0 \%, 1 / 98)$.

For question 7 (What was your impression of the taste and flavor of this drug when it disintegrated in your mouth?), "relatively good" was selected most frequently $(64.1 \%, 59 / 92)$, followed by "relatively bad" $(18.5 \%, 17 / 92)$ 
Question 1: Difficulty taking the current medication $(n=106)$

\begin{tabular}{|c|c|c|}
\hline 14 & 92 & a Yes \\
$(13.2)$ & $(86.8)$ & व No \\
\hline
\end{tabular}

Question 2: Difficulty identifying the current medication $(n=106)$

\begin{tabular}{l|l|l}
7 & 99 & \\
$(6.6)$ & $\square$ Yes \\
& $\square$ No
\end{tabular}

Question 3: Number of drugs taken routinely, including edoxaban film-coated tablet $(n=106)$

\begin{tabular}{|c|c|c|c|}
\hline $\begin{array}{c}10 \\
(9.4)\end{array}$ & $\begin{array}{c}13 \\
(12.3)\end{array}$ & $\begin{array}{c}83 \\
(78.3)\end{array}$ & $\square 2$ types \\
\hline
\end{tabular}

Question 4: Degree of satisfaction with edoxaban OD tablet as compared with edoxaban film-coated tablet $(n=106)$

\begin{tabular}{|c|c|c|}
\hline $\begin{array}{c}37 \\
(34.9)\end{array}$ & $\begin{array}{c}56 \\
(52.8)\end{array}$ & $\begin{array}{c}13 \\
(12.3)\end{array}$ \\
\hline
\end{tabular}

Question 5: Ease in identifying edoxaban OD tablet $(n=105)$

\begin{tabular}{|c|c|c|c|}
\hline 28 & 29 & 16 & 32 \\
$(26.7)$ & $(27.6)$ & $(15.2)$ & $(30.5)$ \\
\hline
\end{tabular}

$\square$ Quite easy

Gasier than the current edoxaban film-coated tablet

$\square$ More difficult than the current edoxaban film-coated tablet

$\square$ Quite difficult

Question 6: Size of edoxaban OD tablet $(n=98)$

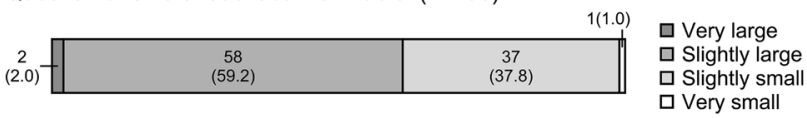

Question 7: Taste/flavor of edoxaban OD tablet $(n=92)$

\begin{tabular}{|c|c|c|}
\hline $\begin{array}{c}16 \\
(17.4)\end{array}$ & $\begin{array}{c}59 \\
(64.1)\end{array}$ & $\begin{array}{c}17 \\
(18.5)\end{array}$ \\
\hline
\end{tabular}

Question 8: Ease in taking edoxaban OD tablet as compared with edoxaban film-coated tablet $(n=105)$

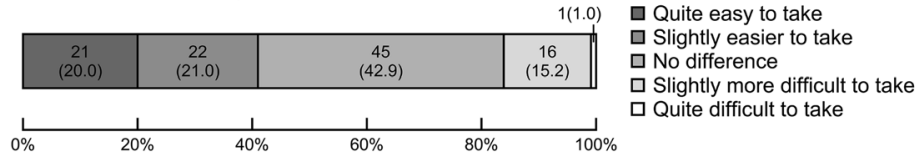

Question 9: Convenience of taking edoxaban OD tablet as compared with edoxaban film-coated tablet $(n=106)$

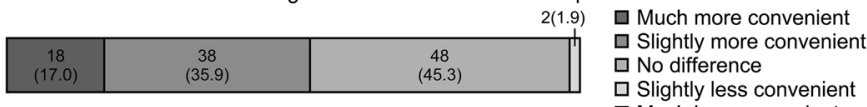

$\square$ Much less convenient

Question 10: Ease in continuing edoxaban OD tablet as compared with edoxaban film-coated tablet $(n=106)$

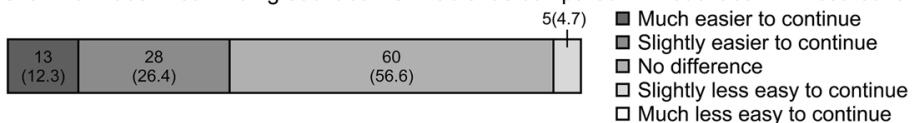

Question 11: Reliability of edoxaban OD tablet as compared with edoxaban film-coated tablet $(n=106)$

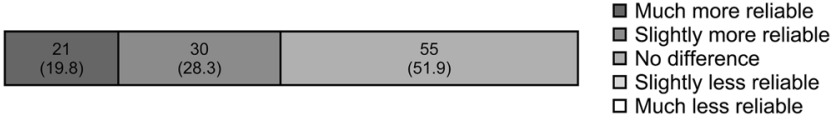

Question 12: Desire to change from edoxaban film-coated tablet to edoxaban OD tablet $(n=95)$

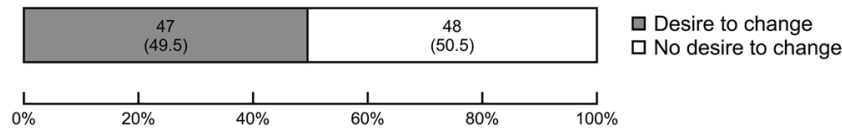

Fig. 1 Results of the sensory evaluation questionnaire survey on edoxaban OD tablets. Values in the bar graph represents the number of patients (\%). OD orally disintegrating 
Table 3 Results of the sensory evaluation questionnaire about edoxaban OD tablets shown by the group

\begin{tabular}{|c|c|c|c|c|c|}
\hline & & $\begin{array}{l}\text { Group } 1(30 \mathrm{mg} \\
\text { without water })^{c} \\
N=32\end{array}$ & $\begin{array}{l}\text { Group } 3(30 \mathrm{mg} \\
\text { with water })^{d} \\
N=32\end{array}$ & $\begin{array}{l}\text { Group } 2(60 \mathrm{mg} \\
\text { without water })^{\mathrm{e}} \\
N=21\end{array}$ & $\begin{array}{l}\text { Group } 4(60 \mathrm{mg} \\
\text { with water })^{f} \\
N=21\end{array}$ \\
\hline & & n (\%) & n (\%) & n (\%) & n (\%) \\
\hline Question 1: Difficulty in ingestion (current) & Yes & $6(18.8)$ & $5(15.6)$ & $2(9.5)$ & $1(4.8)$ \\
\hline & No & $26(81.3)$ & $27(84.4)$ & $19(90.5)$ & $20(95.2)$ \\
\hline Question 2: Difficulty in identifying (current) & Yes & $2(6.3)$ & $3(9.4)$ & $0(0.0)$ & $2(9.5)$ \\
\hline & No & $30(93.8)$ & $29(90.6)$ & $21(100.0)$ & $19(90.5)$ \\
\hline Question 3: Number of drugs taken & 1 type $^{\mathrm{a}}$ & $3(9.4)$ & $3(9.4)$ & $1(4.8)$ & $3(14.3)$ \\
\hline & 2 types & $6(18.8)$ & $2(6.3)$ & $4(19.1)$ & $1(4.8)$ \\
\hline & $\geq 3$ types & $23(71.9)$ & $27(84.4)$ & $16(76.2)$ & $17(81.0)$ \\
\hline Question 4: Degree of satisfaction & Unsatisfactory & $5(15.6)$ & $1(3.1)$ & $7(33.3)$ & $0(0.0)$ \\
\hline & No difference & $15(46.9)$ & $21(65.6)$ & $6(28.6)$ & $14(66.7)$ \\
\hline & Satisfactory & $12(37.5)$ & $10(31.3)$ & $8(38.1)$ & $7(33.3)$ \\
\hline Question 5: Ease in identifying & Quite easy & $7(21.9)$ & $7(21.9)$ & $6(30.0)$ & $8(38.1)$ \\
\hline & Easier $^{\mathrm{b}}$ & $8(25.0)$ & $11(34.4)$ & $7(35.0)$ & $3(14.3)$ \\
\hline & More difficult ${ }^{b}$ & $5(15.6)$ & $3(9.4)$ & $4(20.0)$ & $4(19.1)$ \\
\hline & Quite difficult & $12(37.5)$ & $11(34.4)$ & $3(15.0)$ & $6(28.6)$ \\
\hline Question 6: Size & Very large & $1(3.6)$ & $0(0.0)$ & $0(0.0)$ & $1(5.0)$ \\
\hline & Slightly large & $10(35.7)$ & $19(61.3)$ & $16(84.2)$ & $13(65.0)$ \\
\hline & Slightly small & $16(57.1)$ & $12(38.7)$ & $3(15.8)$ & $6(30.0)$ \\
\hline & Very small & $1(3.6)$ & $0(0.0)$ & $0(0.0)$ & $0(0.0)$ \\
\hline Question 7: Taste at the time & Very good & $5(16.7)$ & $5(20.0)$ & $1(5.3)$ & $5(27.8)$ \\
\hline & Relatively good & $16(53.3)$ & $19(76.0)$ & $12(63.2)$ & $12(66.7)$ \\
\hline & Relatively bad & $9(30.0)$ & $1(4.0)$ & $6(31.6)$ & $1(5.6)$ \\
\hline & Very bad & $0(0.0)$ & $0(0.0)$ & $0(0.0)$ & $0(0.0)$ \\
\hline Question 8: Ease in ingestion & Quite easy to take & $8(25.0)$ & $8(25.8)$ & $2(9.5)$ & $3(14.3)$ \\
\hline & Slightly easier to take & $6(18.8)$ & $8(25.8)$ & $3(14.3)$ & $5(23.8)$ \\
\hline & No difference & $9(28.1)$ & $15(48.4)$ & $9(42.9)$ & $12(57.1)$ \\
\hline & Slightly more difficult to take & $8(25.0)$ & $0(0.0)$ & $7(33.3)$ & $1(4.8)$ \\
\hline & Quite difficult to take & $1(3.1)$ & $0(0.0)$ & $0(0.0)$ & $0(0.0)$ \\
\hline Question 9: Convenience & Much more convenient & $7(21.9)$ & $3(9.4)$ & $2(9.5)$ & $6(28.6)$ \\
\hline & Slightly more convenient & $9(28.1)$ & $15(46.9)$ & $6(28.6)$ & $8(38.1)$ \\
\hline & No difference & $14(43.8)$ & $14(43.8)$ & $13(61.9)$ & $7(33.3)$ \\
\hline & Slightly less convenient & $2(6.3)$ & $0(0.0)$ & $0(0.0)$ & $0(0.0)$ \\
\hline & Much less convenient & $0(0.0)$ & $0(0.0)$ & $0(0.0)$ & $0(0.0)$ \\
\hline Question 10: Ease of continuation & Much easier to continue & $6(18.8)$ & $2(6.3)$ & $1(4.8)$ & $4(19.1)$ \\
\hline & Slightly easier to continue & $6(18.8)$ & $13(40.6)$ & $6(28.6)$ & $3(14.3)$ \\
\hline & No difference & $17(53.1)$ & $17(53.1)$ & $12(57.1)$ & $14(66.7)$ \\
\hline & Slightly less easy to continue & $3(9.4)$ & $0(0.0)$ & $2(9.5)$ & $0(0.0)$ \\
\hline & Much less easy to continue & $0(0.0)$ & $0(0.0)$ & $0(0.0)$ & $0(0.0)$ \\
\hline Question 11: Reliability & Much more reliable & $2(6.3)$ & $7(21.9)$ & $6(28.6)$ & $6(28.6)$ \\
\hline & Slightly more reliable & $11(34.4)$ & $9(28.1)$ & $5(23.8)$ & $5(23.8)$ \\
\hline & No difference & $19(59.4)$ & $16(50.0)$ & $10(47.6)$ & $10(47.6)$ \\
\hline & Slightly less reliable & $0(0.0)$ & $0(0.0)$ & $0(0.0)$ & $0(0.0)$ \\
\hline & Much less reliable & $0(0.0)$ & $0(0.0)$ & $0(0.0)$ & $0(0.0)$ \\
\hline
\end{tabular}


Table 3 Results of the sensory evaluation questionnaire about edoxaban OD tablets shown by the group (Continued)

\begin{tabular}{|c|c|c|c|c|c|}
\hline & & $\begin{array}{l}\text { Group } 1(30 \mathrm{mg} \\
\text { without water })^{c} \\
N=32\end{array}$ & $\begin{array}{l}\text { Group } 3(30 \mathrm{mg} \\
\text { with water })^{\mathrm{d}} \\
N=32\end{array}$ & $\begin{array}{l}\text { Group } 2(60 \mathrm{mg} \\
\text { without water })^{\mathrm{e}} \\
N=21\end{array}$ & $\begin{array}{l}\text { Group } 4(60 \mathrm{mg} \\
\text { with water })^{f} \\
N=21\end{array}$ \\
\hline & & n (\%) & n (\%) & n (\%) & n (\%) \\
\hline \multirow[t]{2}{*}{ Question 12: Desire to change } & Desire to change & $12(44.4)$ & $19(63.3)$ & $6(30.0)$ & $10(55.6)$ \\
\hline & No desire to change & $15(55.6)$ & $11(36.7)$ & $14(70.0)$ & $8(44.4)$ \\
\hline
\end{tabular}

${ }^{a}$ Edoxaban film-coated tablet only

${ }^{b}$ compared with the current medication

cedoxaban OD tablet $30 \mathrm{mg}$ without water

dedoxaban OD tablet $30 \mathrm{mg}$ with water

edoxaban OD tablet $60 \mathrm{mg}$ without water

edoxaban OD tablet $60 \mathrm{mg}$ with water

$O D$ orally disintegrating

and "very good" (17.4\%, 16/92). "Very bad" was not selected by any of the patients. Of the patients who selected "relatively bad," 15 stated that it was "tolerable" and 1 stated that it was "not tolerable." Of the patients who selected "relatively bad," 15 took the tablet without water. The major reasons for responding "good" were "no concerns," "easy to swallow," and "slightly sweet and smoothly dissolving," and those for selecting "relatively bad" were "bitter," "sour," "not dissolving smoothly," and "slightly starchy."

For question 8 (Have you found this drug easier to take than the current medication [edoxaban film-coated tablet]?), "no difference" was selected most frequently (42.9\%, 45/105), followed by "slightly easier to take" (21.0\%, 22/105), "quite easy to take" (20.0\%, 21/105), "slightly more difficult to take" $(15.2 \%, 16 / 105)$, and "quite difficult to take" $(1.0 \%, 1 / 105)$. Of the patients who selected "slightly more difficult to take" or "quite difficult to take," 16 took the tablet without water. The major reasons for selecting "easy to take" were "sweet," "tasty," and "smoothly dissolving," and those for selecting "difficult to take" were "easier to take with water," "bitter," and "not smoothly dissolving."

For question 9 (Do you think that this drug is more convenient to take than the current medication [edoxaban film-coated tablet]?), "no difference" was selected most frequently $(45.3 \%, 48 / 106)$, followed by "slightly more convenient" (35.9\%, 38/106), "much more convenient" (17.0\%, $18 / 106)$, and "slightly less convenient" (1.9\%, 2/106). "Much less convenient" was not selected by any of the patients. The major reasons for selecting "more convenient" were "can be taken without water" and "does not require effort to swallow," and those for selecting "no difference" was "I take it with water, simultaneously with other drugs."

For question 10 (Do you think this drug is easier to continue than the current medication [edoxaban film-coated tablet]?), "no difference" was selected most frequently (56.6\%, 60/106), followed by "slightly easier to continue" (26.4\%, 28/106), "much easier to continue" (12.3\%, 13/106), and "slightly less easy to continue" (4.7\%, 5/106). "Much

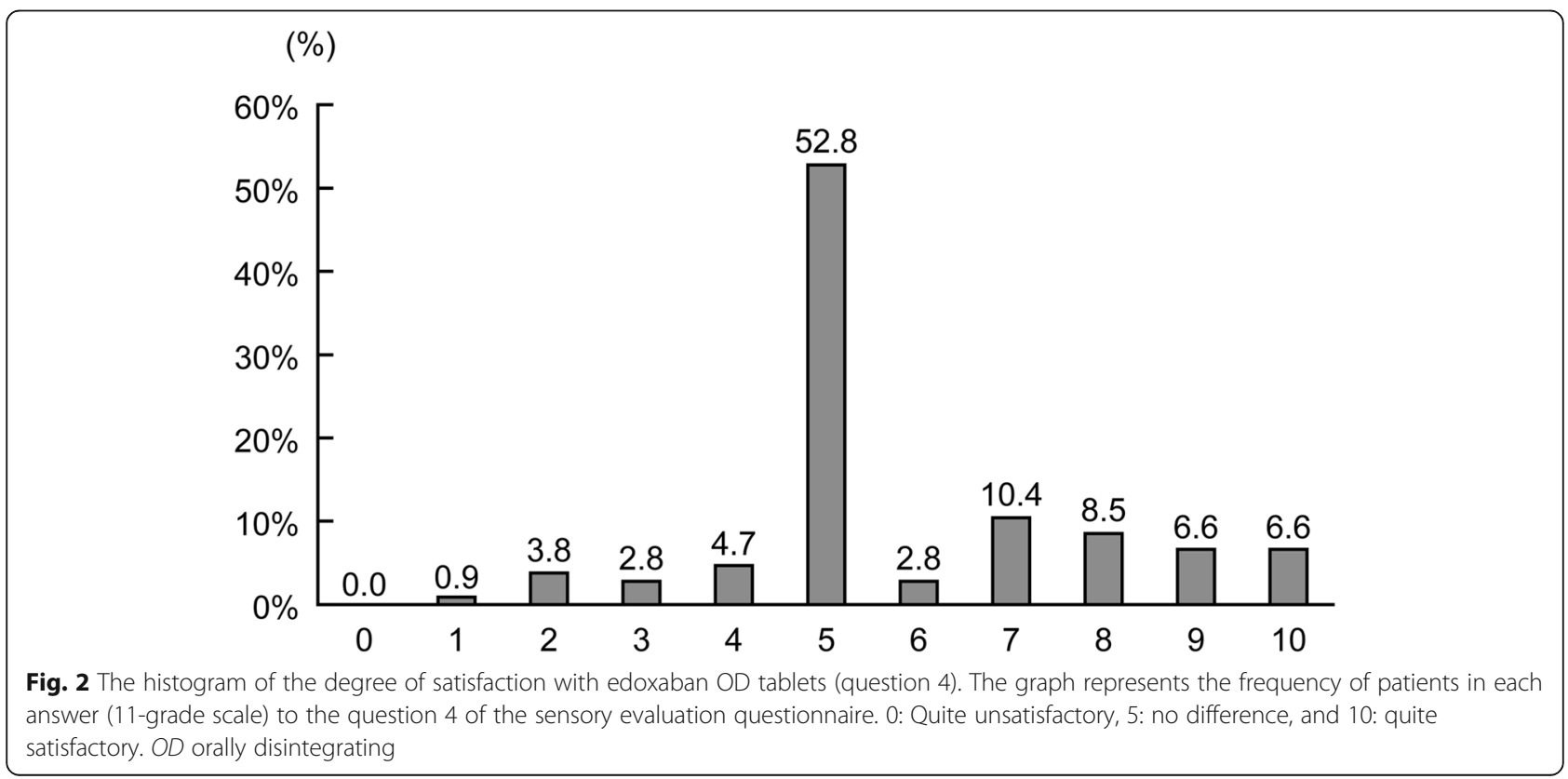


less easy to continue" was not selected by any of the patients. The major reasons for selecting "easier to continue" were "can be taken without water" and "the smoothly dissolving nature may be advantageous," and those for selecting "no difference" were "both existing film-coated tablet and OD tablet are easy to take" and "finds no difference," and those for selecting "slightly less easy to continue" were "bitter" and "it is better when taken with water."

For question 11 (Do you think that the printed product name and dose level on the tablet make this drug more reliable than the current medication [edoxaban film-coated tablet]?), "no difference" was selected most frequently $(51.9 \%, 55 / 106)$, followed by "slightly more reliable" $(28.3 \%, 30 / 106)$ and "much more reliable" (19.8\%, 21/106). "Slightly less reliable" and "much less reliable" were not selected by any of the patients.

For question 12 (This drug will be sold at the same price as the current medication [edoxaban film-coated tablet]. Will you want to change to this drug after marketed?), "No desire to change" was selected by $50.5 \%$ (48/95) and "desire to change" was selected by $49.5 \%$ (47/95). The major reasons for "no desire to change" were "water is needed when taking it together with other drugs," "I have some other drugs to take simultaneously," "it does not taste good," and others, and those for selecting "desire to change" were "easier to take," "less likely to incorrectly identify," and others.

\section{Comparison of sensory evaluation between ingestion with and without water}

The comparison of sensory evaluation between ingestion without water (groups 1 and 2) and with water (groups 3 and 4) is shown in Fig. 3 and Table S1 (Additional file 1). Figure 3 shows the percentages of patients who answered " 5 " (no difference) through "10" (quite satisfactory) in question 4; "1" (very good) or "2" (relatively good) in questions 5 and 7; "1" (very large) or "2" (slightly large) in question 6; "1" (very good) through "3" (no difference) in questions 8-11; and "1" (desire to change) in question 12. The major items found to differ between ingestion with and without water were the degree of satisfaction (question 4), taste and flavor at the time of edoxaban OD tablet disintegration (question 7), ease of ingestion (question 8), and desire a change to edoxaban OD tablets from the current medication (question 12).

"Unsatisfactory" for question 4 (degree of satisfaction) was selected by $1.9 \%(1 / 53)$ and $22.6 \%(12 / 53)$ of the patients who ingested edoxaban OD tablets with and without water, respectively. "Relatively bad" for question 7 (taste and flavor) was selected by $4.7 \%(2 / 43)$ and 30.6\% $(15 / 49)$ of the patients who ingested edoxaban OD tablets with and without water, respectively. "Slightly more difficult to take" or "quite difficult to take" for question
8 (ease of ingestion compared with edoxaban film-coated tablets) was selected by $1.9 \%(1 / 52)$ and $30.2 \%(16 / 53)$ of the patients who ingested the drug with and without water, respectively. "Desire to change" to the OD tablet for question 12 was selected by $60.4 \%(29 / 48)$ and $38.3 \%$ (18/47) of the patients who ingested the drug with and without water, respectively.

\section{Subgroup analysis}

Table 4 shows the results of subgroup analysis of sensory evaluation of edoxaban OD tablets by age $(<75$ and $\geq 75$ years) and response to question 1 (difficulty taking the current medication).

\section{Age $<75$ and $\geq 75$ years}

The major items found to differ between the $<75$ and $\geq 75$ year age groups were reliability (question 11) and the desire to change to the OD tablets (question 12). "Much more reliable" was selected by $29.6 \%(16 / 54)$ of the patients aged $<75$ years and by $9.6 \%(5 / 52)$ of those aged $\geq 75$ years. "Desire to change" to edoxaban the OD tablets for question 12 was selected by $57.1 \%$ (28/49) of the patients aged $<75$ years and by $41.3 \%$ (19/46) of those aged $\geq 75$ years.

\section{Presence/absence of difficulty taking the current medication} The major items found to differ between the patients who perceived difficulty taking the current medication and those who did not perceive difficulty were "ease of ingestion" (question 8), "ease in continuing drug ingestion" (question 10), and "desire change to the OD tablet" (question 12). Regarding the ease of taking edoxaban OD tablets (question 8), "quite easy to take" was selected by $42.9 \%(6 / 14)$ of those who perceived difficulty taking the current medication and $16.5 \%(15 / 91)$ of those who did not. Regarding ease of continuing drug ingestion (question 10), "much easier to continue" was selected by $35.7 \%(5 / 14)$ of those who perceived difficulty taking the current medication and $8.7 \%(8 / 92)$ of those who did not. "Desire to change" to edoxaban OD tablets in question 12 was selected by $76.9 \%(10 / 13)$ of those who perceived difficulty taking the current medication and $45.1 \%(37 / 82)$ of those who did not.

\section{AEs and ADRs}

During the study period, 4 AEs occurred in 4 patients, including palpitation, diarrhea, and chest discomfort (1 event each) in the 30-mg edoxaban OD tablet group and excessive gastrointestinal motility (1 event) in the $60-\mathrm{mg}$ edoxaban OD tablet group. No serious AEs or AEs causally related with edoxaban OD tablets were observed. All AEs were confirmed to be recovered after the end of the study. 


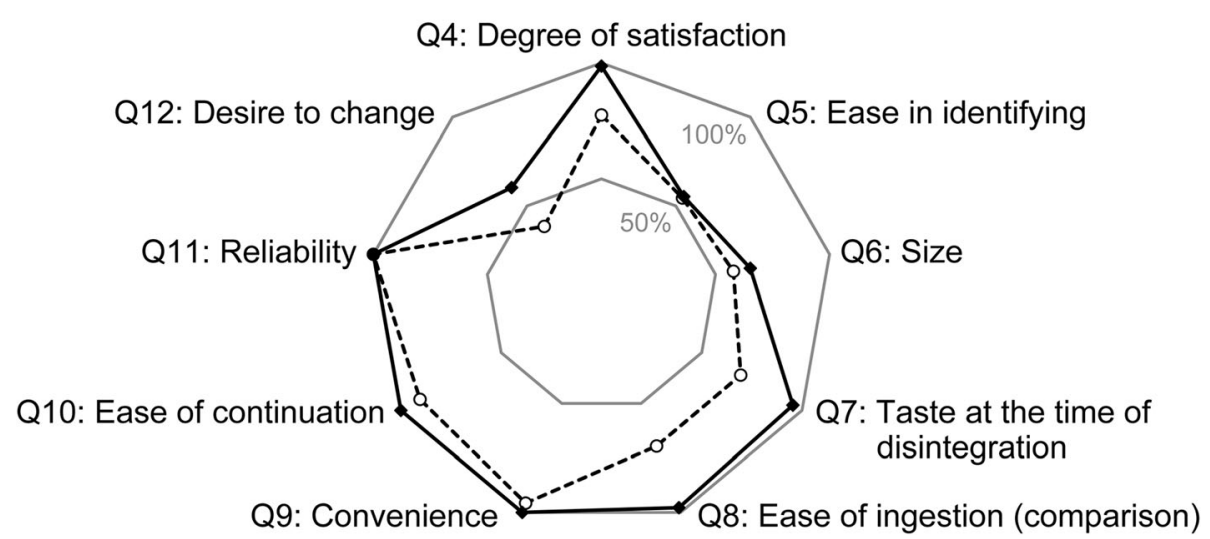

Fig. 3 Comparison of sensory evaluation between groups that ingested edoxaban OD tablets with or without water. The graph shows the percentages of patients who answered " 5 " (no difference) through "10" (quite satisfactory) in question 4; "1" (very good) or "2" (relatively good) in questions 5 and 7; "1" (very large) or "2" (slightly large) in question 6; "1" (very good) through "3" (no difference) in questions 8-11; and "1" (desire to change) in question 12 . OD orally disintegrating, Q question

\section{Discussion}

In this study, the subjects enrolled tended to be older (mean age, $73.0 \pm 8.6$ years; aged $\geq 75$ years, $49.1 \%$ ), particularly those who were allocated to the 30-mg edoxaban OD tablet groups (groups 1 and 3).

For the questionnaires regarding the current medication, $86.8 \%$ of the subjects reported no difficulty taking the current medication (question 1), 93.4\% reported no difficulty identifying the drugs (question 2), and 78.3\% reported taking 3 or more drugs (including edoxaban film-coated tablets) every morning (question 3), which indicates that most of the patients in this study perceived no difficulty taking the current medication including edoxaban filmcoated tablets and had been taking 3 or more drugs.

In question 4 (degree of satisfaction with edoxaban $\mathrm{OD}$ tablets), more than half (52.8\%) of the patients selected "no difference." However, considering that "satisfactory" was selected by $34.9 \%$ in the group that included many patients who perceived no complaint about taking the current medication, the degree of satisfaction with edoxaban OD tablets was considered to be relatively high. The percentage of patients who selected "unsatisfactory" was higher in the group that ingested the drug without water than in the group with water. This result seems to reflect the fact that the rating of taste/flavor (question 7) and ease of ingestion (question 8) was frequently lower in the group that ingested the drug without water. Furthermore, the responses suggest that the patients who usually ingested drugs with water had not been accustomed to taking drugs without water.

In question 5 (ease in identifying edoxaban OD tablets), "quite difficult to identify" was selected most frequently (30.5\%), but "quite easy to identify" or "easier to identify than the current edoxaban film-coated tablet" was selected by 26.7 and $27.6 \%$ of the respondents, respectively. Thus, the answers to this question were equally divided among the opposing responses. This response probably reflected the fact that the figures printed on the tablets were considered too small for some patients to read.

In question 6 (size of edoxaban OD tablets), the percentage of those who selected "slightly large" $(59.2 \%)$ or "slightly small" (37.8\%) was $97 \%$, which suggests that the size of these tablets was acceptable on the whole.

In question 7 (taste and flavor at the time of edoxaban OD tablet disintegration), the percentage of selecting "very good" or "relatively good" was $81.5 \%$. Of the 17 patients who selected "relatively bad," 15 answered "tolerable," which suggests no problem with the taste/flavor of this product. The percentage of selecting "relatively bad" was higher in the group that ingested edoxaban OD tablets without water than in the group that ingested it with water. The rating tended to be higher in the group that ingested edoxaban OD tablets with water. The patients who selected "good" for the taste/flavor tended to select "easier to take" in question 8, which suggests that the taste or flavor affected the perceived ease of OD tablet ingestion.

In question 8 (ease of taking edoxaban OD tablets), "no difference" was selected most frequently (42.9\%), but the percentage with a favorable impression ("easier to take") was higher than the percentage with a bad impression, which suggests that edoxaban OD tablets were easier to take. Since the percentage of selecting "difficult to take" was higher in the group that ingested edoxaban OD tablets without water than in the group that ingested edoxaban OD tablets with water, the rating tended to be higher in the group that ingested edoxaban OD tablets with water. 
Table 4 Results of the sensory evaluation questionnaire about edoxaban OD tablets shown by subgroup

\begin{tabular}{|c|c|c|c|c|c|}
\hline & & \multirow[t]{2}{*}{$\begin{array}{l}\text { Age }(<75 \text { years }) \\
N=54\end{array}$} & \multirow[t]{2}{*}{$\begin{array}{l}\text { Age ( } \geq 75 \text { years }) \\
N=52\end{array}$} & \multicolumn{2}{|c|}{$\begin{array}{l}\text { Current difficulty in ingestion } \\
\text { (Question 1) }\end{array}$} \\
\hline & & & & Yes $N=14$ & No $N=92$ \\
\hline & & n (\%) & n (\%) & n (\%) & n (\%) \\
\hline \multirow[t]{2}{*}{ Question 1: Difficulty in ingestion (current) } & Yes & $6(11.1)$ & $8(15.4)$ & $14(100.0)$ & $0(0.0)$ \\
\hline & No & $48(88.9)$ & $44(84.6)$ & $0(0.0)$ & $92(100.0)$ \\
\hline \multirow[t]{2}{*}{ Question 2: Difficulty in identifying (current) } & Yes & $2(3.7)$ & $5(9.6)$ & $2(14.3)$ & $5(5.4)$ \\
\hline & No & $52(96.3)$ & $47(90.4)$ & $12(85.7)$ & $87(94.6)$ \\
\hline \multirow[t]{3}{*}{ Question 3: Number of drugs taken simultaneously } & 1 type ${ }^{a}$ & $2(3.7)$ & $8(15.4)$ & $1(7.1)$ & $9(9.8)$ \\
\hline & 2 types & $7(13.0)$ & $6(11.5)$ & $2(14.3)$ & $11(12.0)$ \\
\hline & $\geq 3$ types & $45(83.3)$ & $38(73.1)$ & $11(78.6)$ & $72(78.3)$ \\
\hline \multirow[t]{3}{*}{ Question 4: Degree of satisfaction } & Unsatisfactory & $7(13.0)$ & $6(11.5)$ & $1(7.1)$ & $12(13.0)$ \\
\hline & No difference & $27(50.0)$ & $29(55.8)$ & $6(42.9)$ & $50(54.4)$ \\
\hline & Satisfactory & $20(37.0)$ & $17(32.7)$ & $7(50.0)$ & $30(32.6)$ \\
\hline \multirow[t]{4}{*}{ Question 5: Ease in identifying } & Quite easy & $17(31.5)$ & $11(21.6)$ & $5(35.7)$ & $23(25.3)$ \\
\hline & Easier $^{\mathrm{b}}$ & $13(24.1)$ & $16(31.4)$ & $5(35.7)$ & $24(26.4)$ \\
\hline & More difficult ${ }^{b}$ & $11(20.4)$ & $5(9.8)$ & $1(7.1)$ & $15(16.5)$ \\
\hline & Quite difficult & $13(24.1)$ & $19(37.3)$ & $3(21.4)$ & $29(31.9)$ \\
\hline \multirow[t]{4}{*}{ Question 6: Size } & Very large & $2(3.8)$ & $0(0.0)$ & $0(0.0)$ & $2(2.4)$ \\
\hline & Slightly large & $34(64.2)$ & $24(53.3)$ & $7(53.9)$ & $51(60.0)$ \\
\hline & Slightly small & $17(32.1)$ & $20(44.4)$ & $6(46.2)$ & $31(36.5)$ \\
\hline & Very small & $0(0.0)$ & $1(2.2)$ & $0(0.0)$ & $1(1.2)$ \\
\hline \multirow[t]{4}{*}{ Question 7: Taste at the time of disintegration } & Very good & $9(18.4)$ & $7(16.3)$ & $2(14.3)$ & $14(18.0)$ \\
\hline & Relatively good & $31(63.3)$ & $28(65.1)$ & $11(78.6)$ & $48(61.5)$ \\
\hline & Relatively bad & $9(18.4)$ & $8(18.6)$ & $1(7.1)$ & $16(20.5)$ \\
\hline & Very bad & $0(0.0)$ & $0(0.0)$ & $0(0.0)$ & $0(0.0)$ \\
\hline \multirow[t]{5}{*}{ Question 8: Ease of ingestion (comparison) } & Quite easy to take & $10(18.9)$ & $11(21.2)$ & $6(42.9)$ & $15(16.5)$ \\
\hline & Slightly easier to take & $14(26.4)$ & $8(15.4)$ & $3(21.4)$ & $19(20.9)$ \\
\hline & No difference & $22(41.5)$ & $23(44.2)$ & $3(21.4)$ & $42(46.2)$ \\
\hline & Slightly more difficult to take & $6(11.3)$ & $10(19.2)$ & $2(14.3)$ & $14(15.4)$ \\
\hline & Quite difficult to take & $1(1.9)$ & $0(0.0)$ & $0(0.0)$ & $1(1.1)$ \\
\hline \multirow[t]{5}{*}{ Question 9: Convenience } & Much more convenient & $8(14.8)$ & $10(19.2)$ & $4(28.6)$ & $14(15.2)$ \\
\hline & Slightly more convenient & $22(40.7)$ & $16(30.8)$ & $6(42.9)$ & $32(34.8)$ \\
\hline & No difference & $23(42.6)$ & $25(48.1)$ & $4(28.6)$ & $44(47.8)$ \\
\hline & Slightly less convenient & $1(1.9)$ & $1(1.9)$ & $0(0.0)$ & $2(2.2)$ \\
\hline & Much less convenient & $0(0.0)$ & $0(0.0)$ & $0(0.0)$ & $0(0.0)$ \\
\hline \multirow[t]{5}{*}{ Question 10: Ease of continuation } & Much easier to continue & $6(11.1)$ & $7(13.5)$ & $5(35.7)$ & $8(8.7)$ \\
\hline & Slightly easier to continue & 16 (29.6) & $12(23.1)$ & $2(14.3)$ & $26(28.3)$ \\
\hline & No difference & $29(53.7)$ & $31(59.6)$ & $7(50.0)$ & $53(57.6)$ \\
\hline & Slightly less easy to continue & $3(5.6)$ & $2(3.9)$ & $0(0.0)$ & $5(5.4)$ \\
\hline & Much less easy to continue & $0(0.0)$ & $0(0.0)$ & $0(0.0)$ & $0(0.0)$ \\
\hline \multirow[t]{5}{*}{ Question 11: Reliability } & Much more reliable & $16(29.6)$ & $5(9.6)$ & $5(35.7)$ & $16(17.4)$ \\
\hline & Slightly more reliable & $16(29.6)$ & $14(26.9)$ & $2(14.3)$ & $28(30.4)$ \\
\hline & No difference & $22(40.7)$ & $33(63.5)$ & $7(50.0)$ & $48(52.2)$ \\
\hline & Slightly less reliable & $0(0.0)$ & $0(0.0)$ & $0(0.0)$ & $0(0.0)$ \\
\hline & Much less reliable & $0(0.0)$ & $0(0.0)$ & $0(0.0)$ & $0(0.0)$ \\
\hline
\end{tabular}


Table 4 Results of the sensory evaluation questionnaire about edoxaban OD tablets shown by subgroup (Continued)

\begin{tabular}{|c|c|c|c|c|c|}
\hline & & \multirow[t]{2}{*}{$\begin{array}{l}\text { Age (<75 years }) \\
N=54\end{array}$} & \multirow[t]{2}{*}{$\begin{array}{l}\text { Age }(\geq 75 \text { years }) \\
N=52\end{array}$} & \multicolumn{2}{|c|}{$\begin{array}{l}\text { Current difficulty in ingestion } \\
\text { (Question 1) }\end{array}$} \\
\hline & & & & Yes $N=14$ & No $N=92$ \\
\hline & & n (\%) & n (\%) & n (\%) & n (\%) \\
\hline \multirow[t]{2}{*}{ Question 12: Desire to change } & Desire to change & $28(57.1)$ & $19(41.3)$ & $10(76.9)$ & $37(45.1)$ \\
\hline & No desire to change & $21(42.9)$ & $27(58.7)$ & $3(23.1)$ & $45(54.9)$ \\
\hline
\end{tabular}

${ }^{a}$ Edoxaban film-coated tablet only

${ }^{\mathrm{b}}$ compared with the current medication

$O D$ orally disintegrating

In question 9 (convenience of taking edoxaban OD tablets), "no difference" was selected most frequently (45.3\%). However, the percentage of patients selecting "more convenient" was also high (52.8\%), which suggests that edoxaban OD tablets were perceived as more convenient than the existing edoxaban film-coated tablets.

In question 10 (ease of continuation to take edoxaban OD tablets), "no difference" was selected most frequently (56.6\%). However, the percentage of patients who selected "easier to continue" was relatively high (38.7\%), which suggests that edoxaban OD tablets tented to be perceived as easy to continue.

In question 11 (reliability of edoxaban OD tablets), "no difference" was selected most frequently (51.9\%). As the only other answer was "more reliable" (indicating a favorable impression), edoxaban OD tablets were considered reliable for reasons such as printing the product name on the tablets.

In question 12 (desire a change to edoxaban OD tablets), $49.5 \%$ of the respondents selected "desire to change" and approximately the same percentage selected "no desire to change." Thus, 2 opposing answers were selected by a similar percentage. The desire to change tended to be more common in the group that ingested edoxaban OD tablets with water than in the group that ingested the edoxaban OD tablet without water. The reason for selecting "desire to change" was "easier to take" in most patients, probably reflecting sufficient understanding of the features of OD tablets. The reasons for selecting "no desire to change" were as follows: "water is needed when taking it with other drugs," "I have other drugs to take simultaneously," "it is easier to take with water," and others. These answers suggest that the features of OD tablets (can be taken with water simultaneously with other drugs) had not been sufficiently understood by these patients.

In this study, $90 \%$ of the patients had been routinely taking 2 or more tablets, and most of the patients seemed to have been taking edoxaban tablets with water simultaneously with other drugs. For this reason, taking edoxaban OD tablets with water seems to be closer to the actual clinical setting for these patients. This study shows that the degree of satisfaction, taste/flavor, and ease of ingestion were rated higher in the group that ingested the drug with water, which suggests that the advantages of edoxaban OD tablets are better manifested when it is taken with water. As a result, it is inferred that many of the patients desired a change to edoxaban OD tablets in the group taking edoxaban OD tablets with water.

Generally, OD tablets are more advantageous for elderly patients and patients with impaired swallowing function due to cerebral infarction or other reasons. Therefore, we conducted a subgroup analysis according to the ages $(<75$ and $\geq 75$ years) and presence/absence of difficulty of taking current medications. In patients aged $\geq 75$ years, the rating of reliability and percentage of desiring a change were low, with no item recording a high rating. In patients who perceived difficulty of taking current medications, the percentage of desiring a change to edoxaban OD tablets was as high as $76.9 \%$. These results suggest that the advantages of edoxaban OD tablets were rated high by the patients who perceived difficulty taking current medications.

There are some limitations in this study. The first is that the condition for drug ingestion (designed to take edoxaban OD tablet as a single agent) differed from the actual clinical setting. Most patients were taking 2 or more tablets routinely and probably took edoxaban tablets and other medications simultaneously with water. Irikura et al. [7] investigated whether there are advantages of OD tablets for patients taking multiple drugs simultaneously and reported that $40 \%$ of medical professionals (physicians, nurses, and pharmacists) perceived no advantage of OD tablets, while $30 \%$ perceived some advantages. They additionally reported that the perceived advantages included easier ingestion if at least one drug is an OD tablet or the ability to take OD tablets without water even if it is at least one of the drugs, among others. We therefore consider it necessary to evaluate the advantages of edoxaban OD tablets under conditions of multiple drug ingestion simultaneously with water identical to that in a practical clinical setting. The second is that only 2 hospitals participated in this study, and the number of patients enrolled was limited (including only 1 woman in the 60-mg edoxaban OD tablet group). Therefore, general extrapolation of the results of this study might be difficult. A further large-scale study would be needed, especially enrolling more women in the 60-mg edoxaban OD tablet group. The third is that we 
cannot rule out the possibility that the features of edoxaban OD tablets (can be taken with water simultaneously with other drugs) had not been understood sufficiently by the participants. Different results may be obtained if a similar study is conducted in actual clinical practice, in which patients would be adequately informed about the possibility of taking these tablets with water.

\section{Conclusions}

A questionnaire survey was conducted to assess edoxaban OD tablets in a study population that included many patients who perceived no difficulty taking the existing film-coated tablets. The degree of satisfaction and rating of taste/flavor, ease of ingestion, convenience, ease of continuation, and reliability were high on the whole, with about half of all the patients reporting a desire to change to edoxaban OD tablets. The rating of these features was higher in the group that ingested the drug with water than in the group without water. The percentage of patients who desired a change to edoxaban OD tablet was higher among those who perceived difficulty taking current medications. Similar results were reported in past studies of sensory evaluation for other OD tablets [4-6]. Moreover, a change to OD tablets from existing standard tablets has been reported to increase medication adherence to dosing instructions, resulting in better treatment responses $[2,3]$. We may therefore expect that the use of edoxaban OD tablets will improve the patient adherence to medication and outcomes.

\section{Additional file}

Additional file 1: Table S1. Results of the sensory evaluation questionnaire about edoxaban $\mathrm{OD}$ tablets shown by dose level (30 mg/60 mg) and with/without water. (DOCX $24 \mathrm{~kb}$ )

\section{Abbreviations}

ADR: Adverse drug reaction; AE: Adverse event; DOAC: Direct oral anticoagulant; OD: Orally disintegrating

\section{Acknowledgments}

This article is an English translation of the article originally reported in Therapeutic Research in Japanese (Yamashita T, Hagii J, Morishima Y, Akasaka T, Matsumoto T, Kimura T. Clinical study of sensory evaluation using edoxaban orally disintegrating tablet [OD tablet]. 2018; 39:399-417), not including the description of (1) the reasons for desiring or not desiring the change to edoxaban $\mathrm{OD}$ tablet from the current medication and (2) the subgroup analysis of sensory evaluation of edoxaban OD tablet by prior cerebral infraction (presence vs. absence) and the number of drug types taken routinely ( 1 type vs. $\geq 2$ types). The authors are indebted to Sogo Rinsho Medefi Co., Ltd. for their support in drafting and writing the original manuscript written in Japanese. The medical writing assistance in editing and styling the manuscript was performed by inscience Communications, Springer Healthcare, and was funded by Daiichi Sankyo Co., Ltd.

\section{Funding}

This study and the medical writing assistance with the manuscript were funded by Daiichi Sankyo Co., Ltd.

\section{Availability of data and materials}

The datasets used and/or analyzed during the present study are available from the corresponding author on reasonable request.

\section{Authors' contributions}

TY and JH established the study concept and design, conducted the research process, acquired and interpreted the data, and reviewed the manuscript. YM established the study concept and design, managed and coordinated research activities, interpreted the data, and contributed to drafting of the manuscript. TA and TK established the study concept and design, managed and coordinated the research activity, interpreted the data, and reviewed the manuscript. TM analyzed and interpreted the data. All authors read and approved the final manuscript.

Ethics approval and consent to participate

The study was conducted in compliance with the ethical principles stated in the Declaration of Helsinki (revised in 2013), the International Conference on Harmonisation Good Clinical Practice Guidelines, the Ethical Guidelines for Medical and Health Research Involving Human Subjects (Partially Amended on February 28, 2017), and the protocol for this study. The appropriateness of this study was reviewed and approved by the ethics committee of each participating facility. Written informed consent was obtained from all participants in this study.

\section{Consent for publication}

Not applicable.

\section{Competing interests}

This study was planned and funded by Daiichi Sankyo Co., Ltd. It was implemented as a company-initiated clinical study. EP-CRSU Co., Ltd. oversaw the monitoring, data management, statistical analysis, and other duties. Audit was conducted by Linical Co., Ltd. TY has received research funds from Bristol-Myers Squibb Company, Bayer HealthCare, Daiichi Sankyo Co., Ltd., and Mitsubishi-Tanabe Pharma Corporation; and remuneration from Daiichi Sankyo Co., Ltd., Bayer HealthCare, Pfizer Japan Inc., Bristol-Myers Squibb Company, Boehringer Ingelheim Co., Ltd., Eisai Co., Ltd., TOA EIYO LTD., Takeda Pharmaceutical Company Limited, and ONO PHARMACEUTICAL CO., LTD. JH has received speakers' bureau honoraria from Daiichi Sankyo Co., Ltd., Boehringer Ingelheim Co., Ltd., Bayer Healthcare, Bristol-Myers Squibb Company, and Pfizer Japan Inc. YM, TA, TM, and TK are employees of Daiichi Sankyo Co., Ltd.

\section{Publisher's Note}

Springer Nature remains neutral with regard to jurisdictional claims in published maps and institutional affiliations.

\section{Author details}

${ }^{1}$ The Cardiovascular Institute, 3-2-19, Nishiazabu, Minato-ku, Tokyo 106-0031, Japan. ${ }^{2}$ Hirosaki Stroke and Rehabilitation Center, 1-2-1, Ougi-machi, Hirosaki, Aomori 036-8104, Japan. ${ }^{3}$ Daiichi Sankyo Co., Ltd., 3-5-1, Nihonbashi Honcho, Chuo-ku, Tokyo 103-8426, Japan.

Received: 26 September 2018 Accepted: 18 January 2019 Published online: 15 February 2019

\section{References}

1. Taniguchi H, Magara J, Inoue M. Dysphagia in elderly people [in Japanese]. J Jpn Soc Parenter Enteral Nutr. 2013;28:1069-74.

2. Kinon BJ, Hill AL, Liu H, Kollack-Walker S. Olanzapine orally disintegrating tablets in the treatment of acutely ill non-compliant patients with schizophrenia. Int J Neuropsychopharmacol. 2003;6:97-102.

3. Koh N, Sakamoto S, Chino F. Improvement in medication compliance and glycemic control with voglibose oral disintegrating tablet. Tohoku $J$ Exp Med. 2008;216:249-57.

4. Suzuki H, Muraki K, Matsuoka O, Ano R, Kitada M, Koshio Z. Sensory evaluation of Diovan orally integrating tablet (OD tablet) [in Japanese]. J New Remedies Clin. 2013;62:642-8.

5. Ichikawa Y, Matsuoka O, Matsuda A, Nakajima A, Tashiro N, Kitada M. Sensory evaluation of orally disintegrating (OD) Exforge combination tablet [in Japanese]. J N Remedies Clin. 2015;64:16-23. 
6. Oda H, Matsumoto T, Harada J. A clinical study of sensor evaluation of olmesartan medoxomil orally disintegrating tablet (OD tablet) in patients with hypertension receiving olmesartan medoxomil tablet [in Japanese]. Ther Res. 2016;37:293-302.

7. Irikura M, Ishizuka Y, Kasano M, Kakuta T, Irie T. Clinical needs of drug preparations easier to take, focusing on orally disintegrating tablets [in Japanese]. Pharmaceuticals Monthly. 2008:50:1669-76.

Ready to submit your research? Choose BMC and benefit from:

- fast, convenient online submission

- thorough peer review by experienced researchers in your field

- rapid publication on acceptance

- support for research data, including large and complex data types

- gold Open Access which fosters wider collaboration and increased citations

- maximum visibility for your research: over $100 \mathrm{M}$ website views per year

At $\mathrm{BMC}$, research is always in progress.

Learn more biomedcentral.com/submissions 